\title{
Framing the Economic Sustainability of Oil Economies
}

\author{
Giacomo Luciani
}

\section{Introduction: My First Visit to Abu Dhabi}

I first visited Abu Dhabi in the early 1980s, traveling with an economist colleague and friend. As we were driving into town, I was pleasantly surprised at the greenery along the streets (which was a priority for Sheikh Zayed, the Amir) and the well laid-out urban environment (which has become more chaotic in the intervening decades), and positively commented on it. Yet my friend objected: "But you see, Giacomo, this will all revert to dust as soon as oil is finished". That was also the time when The Economist was advising Kuwait not to invest in the country, as it would be futile anyhow, and the prevailing opinion was that Saudi Arabia would never succeed in establishing a petrochemical industry.

The stereotype according to which Gulf oil economies are not sustainable continues to be widely maintained. The original fear that "oil at some

\footnotetext{
G. Luciani $(\bowtie)$

Graduate Institute of International and Development Studies, Geneva, Switzerland

Paris School of International Affairs, Sciences Po, Paris, France e-mail: giacomo.luciani@graduateinstitute.ch

(C) The Author(s) 2021

G. Luciani, T. Moerenhout (eds.), When Can Oil Economies Be

Deemed Sustainable?, The Political Economy of the Middle East, https://doi.org/10.1007/978-981-15-5728-6_2
} 
point will run out" has lately been replaced by the expectation that oil will lose all economic value because of global warming and "unburnable carbon", but the essence of the narrative has not changed.

The unsustainability mantra is rooted in the poor understanding of economics and the way markets work. There has never been in contemporary history a country that has reverted to dust. Economies are constantly adapting to changing circumstances, and no economy is sustainable in its steady state if no change is allowed. The same is true for political systems: some systems are more flexible and capable of adapting gradually, while others are rigid and may cause forfeiting potential growth for a period of time-but eventually change comes about. In some (too numerous) cases, resistance to change, or the inability to agree on the governance of it, has led to violent conflict entailing extensive losses of capital and human life. In some such cases, however, the economic recovery process has been swift and has opened the door to phases of relative prosperity.

This chapter elaborates on what sustainability actually entails. I devote the second section to the simple but frequently forgotten truth that no economy is sustainable without change, thus putting the case of the Gulf oil economies in a broader global perspective; the third section is devoted to the importance of identifying the needed change in order to be able to discuss the appropriate development strategies. While the standard line is that the Gulf oil economies have not diversified and "remain too dependent on oil", I argue in the fourth section that measurable and significant diversification has taken place. While further diversification in the composition of GDP and exports is certainly needed, an ongoing process is underway in this direction.

The fifth section discusses the standard economic threat that resourcerich countries must cope with, that is, the so-called Dutch disease. The Gulf oil countries have quite successfully dealt with it through a strategy of investment in infrastructure and almost unlimited importation of expatriate labor. The latter has caused its own problems, social and economicnotably a pattern of declining productivity, which is discussed in Sect. 6. This pattern must be reversed because, in the longer run, it is incompatible with a growing GDP per capita. This, I argue, is by far the most important challenge that these economies must now face.

In the seventh section, I discuss excessive dependence on hydrocarbons in the generation of aggregate value added, and argue that it is not an intractable problem. The Gulf economies have abundant opportunities to decarbonize domestic energy consumption as well as the production and transformation of hydrocarbons. Systematically embracing the capture of 
$\mathrm{CO}_{2}$ to avoid emissions in the atmosphere, and using captured $\mathrm{CO}_{2}$ in enhanced oil recovery (EOR), possibly including also the use of imported $\mathrm{CO}_{2}$ captured elsewhere in the world, makes the production of negativeemissions hydrocarbons technically possible (albeit expensive and currently uneconomic). The progressive transformation of crude oil and gas into non-fuel products or hydrogen, and the possible advent of a hydrogen economy, may eventually eliminate emissions from burning hydrocarbons directly.

It is therefore quite possible that hydrocarbons will retain economic value for decades to come, while their use evolves in ways that make it compatible with maintaining global warming within the limits mandated by the Paris Agreement and supported by climate science. This, however, would certainly entail an increase in the cost of production and correspondingly a reduction of the net rent accruing to the treasury of the major producing countries. In the eighth section, I argue that, combined with growing population, gradually declining access to rent implies that states whose financial wherewithal continues to be highly dependent on the oil rent must urgently develop fiscal tools to extract revenue from the domestic economy. This entails the progressive reversal of the rentier state paradigm, whereby the state economically supports society, to a more common situation of society paying for the state. This reversal is unlikely to happen without concomitant evolution of the political order away from patrimonial absolute monarchies to a situation in which, while monarchies may well remain in place, some form of accountability will need to be enforced. Hence, if one assumes that no political evolution is possible, then surely the Gulf oil states are fiscally unsustainable-but no political order can endure unchanged in the face of changing circumstances.

The need to raise taxes mandates a degree of separation between the State and its taxed subjects. Taxes cannot be raised exclusively or primarily on government employees and state-owned enterprises: a genuinely independent and competitive private sector must develop, which is capable of walking on its own legs and not depend solely on government procurement. As discussed in the ninth section, government policies toward the private sector have so far allowed for the accumulation of large fortunes but have fallen significantly short of truly empowering the private sector. Priority for state control of strategic assets has hindered privatization of all but marginal activities, and obsession for control and loyalty to the regime prevents the emergence of a truly entrepreneurial bourgeoisie.

Finally, social and political cohesion requires that greater attention be paid to income distribution. In the absence of any income or wealth 
taxation, oil-fueled economic growth has disproportionately favored a minority of citizens, and, after an early period characterized by significant social mobility, all opportunities now seem reserved for the elite. In the last section, I thus discuss the aspect of social sustainability, meaning that the development path must be such that some opportunities for upward mobility are offered also to the many that have been left behind.

\section{No Economy Is Sustainable Without Change}

Economic life is a process of continuous creative destruction, and no economy is sustainable if it does not continuously adapt. Changing consumer demand-and especially evolving technology and the constant introduction of new products-imposes continuous adaptation on all economies. No economy is sustainable unless it adapts continuously to changing circumstances.

Sustainability is therefore closely related to adaptability. Existing comparative advantage may be lost and new comparative advantage acquired: it all depends on investment decisions, based on starting circumstances. Protecting existing competitive advantages or acquiring new ones is more of an art than a science, and it is normal that some competitors will lose ground while others will gain. The losers may eventually disappear, if we are talking about individual companies; but countries do not disappear.

Countries whose economy loses competitiveness will experience a worsening of their trade balance. If not compensated by an inflow of foreign capital or other transfers, their currency will eventually depreciate relative to other currencies. In recent times, many countries have experienced dramatic devaluations until they found a new equilibrium in external accounts.

It should be noted that the Gulf countries enjoy trade surpluses in most years, and their imports include non-essential and non-productive items such as notably weapons systems. They also host large numbers of expatriate workers who generate large flows of remittances, which burden the respective balance of payments (and contribute to inflating imports). That said, the possibility of allowing a devaluation of the respective national currencies has repeatedly been considered (and rejected) in the Gulf Cooperation Council (GCC) countries. Devaluation would discourage imports and improve the competitiveness of some local products.

Devaluations restore competitiveness but damage the purchasing power of all wages paid in the local currency. Hence, countries that lose ground 
in competitiveness generally experience lower growth in income per capita, while countries whose competitiveness is improving experience higher growth in income per capita. Differential growth in income per capita is a common experience, and major changes have taken place since the end of World War II in the relative position of individual countries-generally in the sense that countries that had lower income per capita have been able to reduce the gap separating them from countries with the highest income per capita. Thus, it may be said that the latter have lost competitiveness, but no one would conclude that they are not sustainable.

The question of sustainability for the GCC economies therefore means being able to adapt to changing circumstances, preserving past gains in income per capita for their citizens, and possibly further closing the gap with the richest countries.

\section{Identifying Needed Change}

In this discussion, it is important to exactly identify the nature of the problem in order to suggest the right policy decisions. The economies of the GCC countries are certainly not sustainable if the assumption is that no change will take place-all economies must continuously adapt. Thus, the mantra that GCC economies are not sustainable has limited use in guiding expectations and policies unless the exact nature of the required change is identified.

The literature oscillates between different definitions of nonsustainability, and these do not necessarily converge in a reasonably clear policy agenda. Is the problem linked to the high share of GDP that is generated by the oil and gas sector? Or to the dominant share of oil and gas in total exports? If we conclude so, we should say that sustainability is linked to improved economic diversification. Or is it linked to the belief that oil and gas may lose economic value in a world that needs to rapidly decarbonize? In this case, sustainability may rather be linked to investment to preserve the economic value of hydrocarbons in a decarbonizing world.

Is non-sustainability linked to excessive dependence on expatriate labor combined with unemployment among the nations' youth? Is it related to the phenomenon of declining productivity of labor, which is closely related to dependence on expatriates? In this case, the issue should primarily be viewed as one of reforming labor policies.

Or is non-sustainability primarily linked to government finance-the fact that governments have not developed a system of taxation that may 
progressively wean them from excessive dependence of a possibly declining source of revenue, that is, hydrocarbon rents? In this case, the question should be primarily one of making sure that a taxation base is created and the required imposition system established. It is perfectly possible for the economy to remain competitive and for the state to be unable to extract sufficient revenue from it with appropriate taxes.

\section{Diversification Has Taken Place}

Contrary to the frequent assertion that the Gulf economies have not diversified as evidenced by their continuing high reliance on oil and gas as shares of both GDP and exports, statistics tell us that significant valueadded diversification has taken place. This is hardly surprising for any observer that is aware of the impoverished and extremely simple status of the economies in question before the advent of the oil era.

The discussion of diversification in oil economies is complicated by the impact of variable oil prices. Whenever prices are high, value added from oil and gas upstream is also increased, more so than value added in the rest of the economy, and it will appear that the economy is losing diversity. Whenever prices are decreasing, the opposite will be the case, and it will show that the economy is now more diversified. Higher oil prices are a good thing for oil-producing countries, notwithstanding the fact that they will appear to be less diversified. In fact, it is not just appearance: the higher prices are a reality and reduced diversification an inevitable consequence. That said, it does not make sense to discuss diversification trends unless price variations are also taken into account. There are no other commodities as important as oil whose price is as volatile as that of oil, otherwise this would be a common problem for many countries.

We therefore need to resort to more complex measures of diversification, as extensively discussed in the chapter by Joerg Beutel in this volume. Although even the more sophisticated indices aimed at measuring the structural interrelations of an economy, such as those based on inputoutput tables, are not immune from reflecting changes in relative prices, their behavior tends to be more stable. Beutel shows that several diversification indices do not tell us that the economies of the GCC countries, in particular Saudi Arabia, are much less diversified than the comparator country Norway.

A converging conclusion is arrived at if we use the Economic Complexity Index (ECI) developed by Ricardo Hausmann and César Hidalgo at 
Harvard and MIT (Hausmann et al. 2014). The index is based on the mapping of what the authors call the products space, in which each product category is mapped in proximity of other products requiring similar technology and know-how, meaning that the producer of one product could relatively easily shift to producing a proximate product. This creates an image in which some products, mostly primary products, appear in isolated positions at the margins, while others, mostly manufactured products, are located in several interlocking clusters at the center. The economic complexity of a country is:

a measure of the knowledge in a society as expressed in the products it makes. The economic complexity of a country is calculated based on the diversity of products a country exports and their ubiquity, or the number of the countries able to produce them (and those countries' complexity). Countries that are able to sustain a diverse range of productive know-how, including sophisticated, unique know-how, are found to be able to produce a wide diversity of goods, including complex products that few other countries can make. (CID, Atlas, Glossary)

The Economic Complexity Index ranks countries based on how diversified and complex their export basket is. Countries that are home to a great diversity of productive know-how, particularly complex specialized knowhow (and including know-how originating from abroad but attracted and implemented locally), will be able to produce a great diversity of sophisticated products.

Table 2.1 ranks key Gulf exporters' ECI scores for 1996 and 2016. The table includes several comparator countries, to highlight the extent to which superficial impressions may be misguided.

There are several interesting points to be noted in this table. To begin with, all oil or commodity exporters, including advanced countries, have low economic complexity because of their relative specialization. Thus, the USA ranks lower than one may expect of the leading techno-economy in the world and will probably show a further decline in the coming years, thanks to Donald Trump's push for "energy dominance" (White House 2019; DOI 2017). It is striking that Mexico is ranked as more complex than Canada, and both are more complex than Norway, which is normally viewed as the success case par excellence among oil exporters. Russia and India are rated barely more complex than Saudi Arabia and the United Arab Emirates. The latter two are doing better than New Zealand, and all 
Table 2.1 Ranking of Gulf countries and selected comparator countries by Economic Complexity Index

\begin{tabular}{lrrrrr}
\hline & \multicolumn{2}{c}{2016} & & \multicolumn{2}{c}{1996} \\
\cline { 2 - 3 } \cline { 5 - 6 } Country & Rank & ECI value & & Rank & ECI value \\
\hline United States & 10 & 1.55 & & 7 & 1.868 \\
Mexico & 21 & 1.11 & & 25 & 0.817 \\
Canada & 35 & 0.696 & & 23 & 0.898 \\
Norway & 39 & 0.638 & & 32 & 0.592 \\
Russian Federation & 48 & 0.235 & & 38 & 0.420 \\
India & 49 & 0.191 & & 56 & 0.007 \\
Saudi Arabia & 50 & 0.171 & & 65 & -0.153 \\
United Arab Emirates & 51 & 0.162 & & 80 & -0.476 \\
New Zealand & 54 & 0.124 & & 42 & 0.313 \\
Oman & 71 & 0.292 & & 82 & -0.510 \\
Kuwait & 73 & 0.314 & & 89 & -0.666 \\
Qatar & 76 & -0.396 & & 109 & -0.955 \\
Australia & 86 & -0.592 & & 60 & -0.026 \\
Iran & 87 & -0.611 & & 106 & -0.915 \\
\hline
\end{tabular}

Source: Center for International Development, Harvard University, Atlas of Economic Complexity, http:// atlas.cid.harvard.edu/.

Gulf Cooperation Council (GCC) countries are doing better than Australia, while Iran does just a bit worse. We normally do not worry about the sustainability of any of the comparator countries (except maybe Russia)-so the Gulf economies may be unsustainable, but lack of economic complexity does not appear to be the reason for it.

Between 1996 and 2016, all Gulf countries, including Iran, significantly improved their ECI position, while all comparator countries except Mexico lost ground. So diversification is indeed happening, and economic complexity is increasing.

As well as other measures of diversification, the ECI is vulnerable to changes in oil prices and quite unstable for major oil exporters-for example, Saudi Arabia ranked 36th in 2004, a year of low oil prices, and 104th in 2008 , a year of peak oil prices. However, oil prices were relatively low in both years compared here (1996 and 2016), so the improvement is clearly not just due to changes in oil prices. Furthermore, oil prices affect all oil exporters, so that GCC improvement relative to other oil exporters must be real. It remains true, however, that low oil prices sustain diversification and high oil prices hinder it. At times of growing oil prices, 
diversification may well be taking place, but it will be obscured by the inflation of value added in the oil sector. When prices decline again, diversification becomes visible.

Some further comments are in order. First, the structural transformation of an economy takes time. Global oil demand may peak in 20 years (at a level above today's), but there is no credible prospect of oil losing economic significance for at least the next 50 years (more on this in Fattouh and Sen's chapter in this book). Diversification may become more challenging after the early successes (it is difficult to gain in diversity when you are diversified to begin with), but we should certainly expect further improvement in the ranking of the Gulf oil exporters. Some massive investment projects that have been undertaken in the past 10 years (such as the Sadara petrochemical j.v. between Saudi Aramco and Dow, the aluminum project going from mining bauxite to rolling mills developed by Maaden in association with Alcoa, or Borouge's new plants in Ruwais) have yet to fully impact export statistics, because of their long gestation and the progressive ramp-up of production.

Second, there are major differences between Gulf oil exporters. The gap in 2016 between Saudi Arabia and Iran is significant. We do not have an ECI for Iraq, but it would surely be much worse than Iran's. And the gap between the Gulf economies and oil exporters elsewhere in the world is even larger: Nigeria ranked 125 (out of 127 countries), Azerbaijan 120, and Angola 116. Not all countries are doing equally well, and relatively few can be said to have made real progress in diversification.

My conclusion is that GDP and export diversification are not good reasons to conclude that the Gulf oil export economies are unsustainable. Of course, the global economy is constantly evolving. Demand, supply, and terms of trade of individual products change constantly, and adaptation is a never-ending task; however, the Gulf economies are diversifying and are today much more adaptable and competitive than they were three or four decades ago. Diversification is happening and likely to continue, progressively reducing dependence on the oil sector-even if oil remains a valuable and important internationally traded commodity.

\section{Dutch Disease and Expatriate Labor}

By "Dutch disease" we mean the appreciation of the real exchange rate as expressed by the relative terms of trade of non-tradable relative to tradable goods and services. The change in the relative terms of trade is caused by 
the emergence of new natural-resource-based exports, which leads to an increase in revenue and domestic expenditure. Because the supply of tradables is elastic, the price is established by international competitive forces and is not expected to change. In contrast, supply of non-tradables is limited in the short term, and increased demand will lead to an increase in their average price. So non-tradables become more expensive than tradables (which is the definition of appreciation of the real exchange rate), and capital is incentivized to move from the production of tradables to that of non-tradables. If a country has a developed tradables sector at the beginning of the process, it may de-industrialize: this is what was feared for the Netherlands when large resources of gas were discovered in the Groningen field. Typically, non-tradables consist of real estate, personal and hospitality services and maybe perishable food products, while tradables consist of all industrial products.

In the short run (defined as the time that it takes for a new investment to take place and increase productive capacity), there is nothing that can be done to prevent the Dutch disease, except refraining from spending the additional revenue from natural resources. This is what Norway has done, but no poor country would reasonably be expected to do the same. The narrative of the Dutch disease is therefore almost invariably supported by empirical observation in the aftermath of a natural resources bonanza: housing and services become very expensive, local craft industry and frequently also agriculture are wiped out, and real estate investment becomes the only game in town. The Gulf countries in the 1970s fully conformed to this pattern.

But in the longer run, when investment can take place and change the economy's production possibility frontier, the real appreciation of the exchange rate may be countered. This can be achieved by expanding the production of non-tradables, thus countering the expected increase in relative prices (Sachs 2007), and importing labor to overcome the limitations in the supply of domestic, especially skilled, workers. The Gulf countries adopted both strategies early on: the state stepped in to quickly increase the supply of non-tradables, and the door was flung open to essentially unlimited importation of expatriate labor (yet with discrimination based on the country of origin).

Coupled with very weak protection of workers' rights, this has meant that the Gulf countries have imported the wage level of their poorer neighbors in Middle East and North Africa (MENA) or South Asia. The end result has been that wage-push inflation has been contained, but 
dependence on expatriates has reached levels not seen anywhere else in the world. Most nationals are employed by the government, but just a few are employed in the private sector in white-collar occupations. Essentially all blue-collar jobs are filled by expatriates, but a significant number of foreigners, mostly skilled, also work for the government.

Is this a sustainable state of affairs? While there will always be foreigners willing to take employment in the Gulf, notwithstanding the sometimes oppressive conditions, such high reliance on expatriates creates significant problems. Expatriates are mostly interested in remitting their incomes to their families and countries of origin; they are very conscious of their precarious state and are reluctant to "take roots" and invest in their host countries, even when this is allowed-and normally it is not. Thus, much of the aggregate wage bill exits the local economy almost immediately, meaning that the Keynesian multiplier is very low.

Secondly, expatriates have an income target and are likely to react to income taxation by simply requesting higher wages or returning to their countries of origin. The latter has been confirmed by the response to increases in fees enacted after the decline in oil prices from 2014. As there is considerable turnaround in the expatriate population, and the wages on offer already are set at the minimum level required to attract them, newcomers will focus on net income if taxes are imposed. This means that taxes on expatriates will end up being paid by employers. In the absence of policies to consolidate the expatriate population (policies which all Gulf governments abhor), foreign residents offer an intermediate, not an ultimate, taxable base.

Thirdly, the abundant supply of low-wage workers is distorting the competitiveness of industry. Investment is attracted in labor-intensive and low-skill activities simply because it is so cheap to hire workers-but these lines of production do not conform to the underlying comparative advantage of the Gulf countries, which is in capital-intensive industries requiring more sophisticated skills. Therefore, their longer-term commercial viability is uncertain to say the least.

\section{The Productivity Issue}

Considering the functioning of the labor market and the almost complete openness to importation of expatriate labor, it is not surprising to see that labor productivity, that is, value added per worker employed, has been declining throughout the Gulf economies, in contrast with the experience 
of almost all other countries in the world (Hertog 2018). The private sector has primarily aimed at minimizing the cost of labor, and has been ready to accept lower skills and qualifications for the sake of lower wages. This has mostly taken the form of shifting hiring practices as in between countries of origin, because the minimum reservation wage of expatriates is frequently related to the average wage in the country of origin.

In economies where the workforce is stable, it is normal to expect a progressive improvement in skills simply due to the permanence in the same job for long periods of time. But the high turnaround rate, which is characteristic of expatriate labor in the Gulf, works in the opposite direction, undermining learning by doing, and actually facilitating the recourse to progressively less skilled laborers, if they come cheaper.

When labor is cheap, there is little incentive to invest in machinery that may improve its productivity. Operating a machine normally requires at least a modicum of training and higher skills, thus improving productivity, which opens the door to higher wages. It also makes the turnaround of workers more difficult, because some retraining might become necessary. Therefore, the attitude has been rather in favor of keeping things simple and basic, avoiding productivity-enhancing investment.

In fact, the cost of labor is so low, and the hassle of recruiting from abroad so significant, that many employers indulge in labor hoarding. Because expatriate workers sometimes desert their employers, either because they somehow find a better job-although this may be against the law-or simply give up and return home, employers want to make sure that they have a certain number of "spare workers" at hand, just in case. This is a recipe for permanently declining productivity.

The meaning of declining productivity is that economic growth is achieved exclusively, thanks to adding to the number of expatriates. While this may allow for expanding the share of GDP accruing to profits in the private sector, it is hardly compatible with improving economic conditions for salaried nationals. Only nationals that possess capital and employ expatriates can benefit from increasing profits. But profits are difficult to tax, and the creation of a taxation base will remain an elusive task.

An economy in which labor productivity constantly declines is therefore not sustainable, because it deprives the state of an easily taxable base. Sustainability requires moving away from extreme reliance on expatriate labor. Labor-saving investment is necessary, coupled with acceptance of progressively higher wages. This in turn will reduce the gap between the wages of nationals and those of expatriates, thus creating conditions for 
overcoming the paradox of high unemployment among nationals, while at the same time so many jobs are taken by expatriates. It may also open the door to the creation of a taxable income base.

\section{Potential for Further Diversification and Defense of Hydrocarbons’ Value}

While the Gulf countries have, comparatively speaking, made good progress in diversifying their economies, the potential for further diversification exists, specifically in the direction of developing industrial activities that may allow the continuing use of hydrocarbons, even while eliminating greenhouse gas emissions and countering climate change. The frequently held opinion according to which only zero use of hydrocarbons may be compatible with zero $\mathrm{CO}_{2}$ emissions may turn out to be unfounded. There are many ways in which the Gulf oil and gas producers may contribute to decarbonization while continuing to use oil and gas.

\subsection{Decarbonize the Production of Oil and Gas}

Growing attention is being devoted to the fact that the production of oil and gas is not equally emission-intensive across regions and fields (Masnadi 2018; IEA 2018a, 73-76). Focusing on the abatement of emissions connected to upstream and midstream activities is a significant strategy in the context of fighting global warming. In the case of gas, special attention has been attracted to reducing or eliminating flaring and venting. In the case of oil, energy requirements connected with fracking for shale oil or use of other enhanced oil recovery methods, and the heat required for the production of heavy oils and oil from bituminous sands have negative consequences for the environment even before the oil or gas is burned. To a large extent, the heat and power for oil and gas production, which is now derived from burning hydrocarbons, could be derived instead from renewable or clean sources. In Oman, the Miraah solar thermal power plant produces steam that is injected in the nearby Amal oil field, and at $1021 \mathrm{MW}$ of capacity, it is one of the largest solar power plants in the world (IEA 2018a, 76; PDO 2017). Steam-based enhanced oil recovery is not very common in the prolific fields of the Gulf, but is likely to be increasingly in use as fields mature and decline. Steam and high temperatures are also needed in refining and petrochemicals. Electric power is 
needed in field operations as well as in transportation by pipeline and in refining and petrochemicals - and it could be derived from renewable or clean sources. While burning hydrocarbons inevitably produces $\mathrm{CO}_{2}$, it may be possible to produce zero- $\mathrm{CO}_{2}$ hydrocarbon fuels in the sense that no $\mathrm{CO}_{2}$ needs to be emitted in the production process.

\subsection{Carbon Capture and Sequestration}

The next logical step is engaging in systematic carbon capture and sequestration (CCS) in the oil and gas fields. The oil industry has extensive experience of capturing $\mathrm{CO}_{2}$ and injecting or re-injecting it in oil and gas fields (IEA 2016; McGlade 2019). This also facilitates the production of oil and gas (KAPSARC 2018), and is therefore either a method of avoiding venting $\mathrm{CO}_{2}$, which is present in the field in association with methane, or of capturing $\mathrm{CO}_{2}$ produced from other sources and sequestering it underground. It is conceivable that all $\mathrm{CO}_{2}$ emitted from burning hydrocarbons in stationary plants may be captured and either used in other industrial uses or sequestered underground in oil and gas fields. If the Gulf oil and gas exporters are keen to preserve the economic value of their resources in a carbon-constrained world, carbon capture and sequestration should be their technology of choice.

In fact, CCS has attracted considerable scholarly interest (FT 2018b), and examples of implementation are slowly coming to the fore. In Abu Dhabi, the $\mathrm{Al}$ Reyadah project takes $\mathrm{CO}_{2}$ from a steel plant owned by Emirates Steel and pumps it to the Rumaitha and Bab oilfields, where it is injected in the ground for enhanced oil recovery (Gulf News 2016). This is just a first, but eventually systematic capture from all plants (power plants first and foremost - at least until oil and gas-fired power plants will still be in use) should be envisaged.

But considering the centrality of CCS for allowing some continued reliance on fossil fuels, the level of engagement of the oil-producing countries (and major international oil corporations) in pursuing deployment of this technology is patently insufficient. Notwithstanding the keen interest in CCS demonstrated by the International Energy Agency and some European oil-producing countries (the UK and Norway) (IEA 2018b), and notwithstanding the multiple studies that have been carried out by research institutions notably in Saudi Arabia, there is not a single major project in the process of being implemented. 
The consequence is that public and even expert opinion does not consider CCS as a viable alternative for global decarbonization. The special report of the IPCC issued in 2018 (IPCC 2018) strongly insists on the need for CCS and negative emissions down the road, and the major producing countries could very well position themselves as potential suppliers of storage services for $\mathrm{CO}_{2}$, including that which may be captured in other countries that might not have appropriate geological sites for this purpose. True, for the time being we do not have a price for carbon sufficient to justify the economics of capturing, transporting, and storing $\mathrm{CO}_{2}$, but hydrocarbon producers need to think strategically and anticipate the market if they wish to convincingly argue that there is a future for their products in a world that needs to rapidly decarbonize

\subsection{Further Integrate Downstream Toward Non-fuel Uses}

A parallel defense strategy consists in emphasizing the use of hydrocarbons to produce products that are not meant for burning as fuels. The palette of oil products has always included lubricants and bitumen, but the major case in this category clearly is that of petrochemicals.

Demand for petrochemicals is growing rapidly in the world, much more rapidly than GDP, and there is little expectation that it may slow down in the coming decades (IEA 2018c). The petrochemical industry is sometimes mistaken for a low-technology industry, and little more than a producer of plastic bags polluting the oceans-but this is a caricature. While production of basic petrochemicals may rely on proven technology, and indeed yield simple products that may damage the environment if not properly recycled (plastic bags and the like), the industry is extremely diversified and increasingly sophisticated, producing an incredible array of materials that find use in almost all manufacturing.

Although polymers can be produced from organic material rather than from fossil feedstock, the prevalence of the latter is unquestionable. Size and plant synergies being essential to competitiveness and product diversification, it is difficult to envisage that the petrochemical industry might move away from reliance on fossil hydrocarbons. To the extent that use of fossil fuels might decline, oil will tend to be cheaper, and petrochemical materials ever more attractive in a wide range of utilizations. Saudi Aramco's and SABIC's effort to develop a crude to petrochemicals refinery (which would essentially produce no fuels) evidently is an early manifestation of this strategy (Arab News 2018). 


\subsection{The Hydrogen Economy}

The final, decisive strategy to preserve the economic value of fossil fuels in a decarbonizing world is to separate them into hydrogen and $\mathrm{CO}_{2}$, capturing the latter and using the former as fuel. Hydrogen is an energy carrier, not a primary energy source, and can be produced starting from several molecules containing it. The perspective of a hydrogen economy has been discussed for decades (IEA 2019), and is normally considered part and parcel of decarbonization strategies, especially in conditions when excess electricity might be available (from excess non-dispatchable renewables or nuclear) for electrolysis of water. The concept of a hydrogen economy thus is relevant even independently of the desire to preserve the economic value of fossil fuels; yet it has considerable synergy with the latter, because, on the one hand, hydrogen is easily produced from light hydrocarbons with steam reforming, a well-established technology( "Natural gas accounts for around three-quarters of the annual global dedicated hydrogen production" IEA 2019, 38), and, on the other hand, hydrogen can substitute for methane in pipeline networks and can be used as transportation fuel in fuel cells-a technology that has considerable advantages in battery electric vehicles for extended range driving.

Oil and gas producers could then position themselves as pioneers of the hydrogen economy, through either exporting hydrogen (presumably in liquid form, unless export pipelines are available), or transforming hydrocarbons into hydrogen close to the final consumer and taking responsibility for the capture, sequestration, or utilization of $\mathrm{CO}_{2}$.

Considered as a whole, these four interlocking strategies for maintaining the economic relevance of hydrocarbons in a decarbonizing world envisage the further profound transformation of the economic structure of the Gulf oil countries. This transformation has not even started yet, and it is not clear that it will be pursued at all. It requires a degree of anticipation and forward looking that the existing governance structures may not be able to provide. Obviously today, the reality of relative prices-notably the absence of a sufficiently high price for carbon and consequent lack of $\mathrm{CO}_{2}$ valorization-does not support massive investment in the direction envisaged. The question remains whether the major Gulf oil producers should not anticipate future global decarbonization policies in view of demonstrating that it may not be necessary to move away from hydrocarbons, rather to change the use that is made of them. 


\section{Need for Developing Taxation}

Even in the perspective that I sketched in the previous section, it is clear that decarbonizing the production of hydrocarbons or turning them into hydrogen for clean burning as fuel will entail significant additional cost, which will go to reduce the size of the rent. In other words, the oil and gas business will come to more closely resemble all other lines of business, where a very significant profit margin is sometimes possible, but not such a huge rent as to allow to almost completely pay for the state from this source alone.

Developing additional sources of revenue requires time and progressive strengthening of the administrative capabilities of the state. Some taxes are easier to collect than others, but the easiest ones-excise taxes on specific categories of goods or taxes on imports-are not sufficient to diversify state revenue to the extent needed. In fact, the Gulf oil-producing countries have recently introduced excises on several goods such as tobacco or sugary beverages, but fuels, which are subjected to large excises in many countries, are made available at relatively low prices (or "subsidized"), and alcoholic beverages - another frequent target of excises-are either restricted or prohibited altogether.

The GCC countries have decided to implement VAT starting at a low level of $5 \%$, but only Bahrain, Saudi Arabia, and the UAE did so. Saudi Arabia further increased VAT to $15 \%$ in July 2020 . VAT is a tax on consumption which is regressive, because higher incomes consume proportionately less, and weighs more on nationals than on expatriates, because the latter are likely to remit or consume abroad a larger share of their income. Other things being equal, a VAT will tend to increase the level of domestic prices and erode the purchasing power of all fixed income earners.

In the end, the imposition of taxes on income and/or wealth for individuals and/or corporations will be inevitable. Taxing corporations may be politically less problematic and administratively simpler, but will meet resistance from domestic entrepreneurs. Subsidiaries of foreign corporations are likely to have ways to shift income to other jurisdictions, or compensate taxes paid locally with deductions in their home countries or other jurisdictions. Local corporations will not enjoy the same financial agility. 
Taxes on personal income will meet with the greatest resistance, and may trigger demands for accountability of power holders and calls for more democratic institutions. In countries where semi-democratic institutions exist, such as Kuwait, the probability of gaining the support of the parliament to enact income taxes is realistically close to nil. Furthermore, as the vast majority of nationals is employed by the state, imposing a tax on their salaries would be equivalent to reducing the same. The net gain would be limited to the revenue that the tax may raise out of income from investment or from salaries of employees of the private sector.

Taxing private sector salaries would contrast with the strategic priority that must be attributed to encouraging nationals to take employment in the private sector. It would however also encourage expatriates to ask for higher wages and eventually possibly help in reducing the wage gap between expatriates and nationals.

Imposing an income tax on expatriates only has been repeatedly considered and rejected. Imposing all wage earners and then offering exemptions or other benefits to nationals employed in the private sector may be a more productive approach. In any case, a personal income tax scheme would need to be strongly progressive to counter the growing inequality of incomes and wealth which is inevitable in the absence of redistribution mechanisms.

A strong argument may be put forward in favor of a wealth tax, both because it would at least conceptually be close to the traditional form of Islamic taxation, that is, zakat, and because a lot of wealth has been accumulated in the form of real estate, which could be easier to assess than financial or other forms of wealth. However, zakat already is levied, at least on paper, and the extent to which it might be increased or administered more effectively is uncertain.

\section{Genuine Reliance on Private Sector}

The need for nurturing a strong base for taxation is the main argument to conclude that economic sustainability eventually requires the consolidation of a competitive and independent private sector. The Gulf oilproducing countries have over decades implemented various converging policies to favor the birth of private entrepreneurs and allow them to amass very sizable fortunes, but the tendency always has been to consider the private sector as an appendix and a client (economically as well as politically) of the state. With the exception of a relatively short period of time 
in the very early years of the current century, when some of the GCC states, including most notably Saudi Arabia, seemed ready to accept a more active role of the local bourgeoisie (Luciani 2005), the state has mostly moved to limit the scope of private initiative in multiple fields that are considered strategic. There has been an almost total disjuncture between an official discourse that always insisted on the role of private enterprises, on privatization, on supporting small and medium enterprises; and the reality of a state profoundly suspicious and unappreciative of the qualities of the national bourgeoisie.

The latest episode in the difficult relationship between the state and holders of political power on the one hand and the entrepreneurs on the other has been the imprisonment of many leading Saudi business people in the Ritz Carlton Hotel in Riyadh and their significant dispossession. This process, which has been carried out with zero transparency and complete disregard of any accepted judicial procedure, has been justified as a cleanup of extensive corrupt practice; however, no specific case of corruption has been made public. The government authorities have repeatedly announced, as proof of success, the fact that assets supposedly worth 100 bn dollars have been sequestered: whether this is in fact the case or not is impossible to say, but the discouraging effect on private investment and initiative in the Kingdom is absolutely certain (FT 2018a).

A radical change of tack is required if the private sector is indeed to become the protagonist of the next phase of economic growth and provide the state with a taxable base capable of offering a source of income in alternative to the oil rent. The will to accept an arm's-length relationship between the state and private enterprises through adherence to the rule of law and promotion of a level playing field is currently not detectable. Under these circumstances, the state is postponing adaptation and again relying on income from oil, plus possibly other international financial placements. This may well work for a time, depending on oil demand and prices, and on how successful the investment decisions of sovereign wealth funds will turn out to be. It may work better for the very high rent per capita countries (Elbadawi and Makdisi in this volume) than for the others. For the latter, the danger is clearly that the shift in attitude may come very late in the day, only when the state will have lost its financial autonomy and will need to solicit the support of the private sector from a position of weakness. 


\section{Tackle Inequality}

The combination of issues related to excessive dependence on expatriate labor, underdevelopment of fiscal tools, and lack of acceptance of a genuinely independent private sector results in a pattern of increasing inequality in the distribution of income and wealth which may translate into growing political discontent.

We have limited systematic information on the distribution of income and wealth in the GCC countries, including because of the absence of direct taxes, which deprives the state of crucial knowledge tools in this respect. But basic facts are very visible. We know that a majority of nationals work for the government, and their wages are not such that you can build a fortune with the savings. They are secure and guaranteed for life by generous retirement schemes that trigger early in life, but do not allow for much luxury. At the opposite extreme, we know that quite a few private entrepreneurs are independently assessed by Forbes to be billionaires or multibillionaires. Some members of the royal family are included in this list, but others would certainly belong to it if Forbes had the information to assess their wealth, or they cared to appear in it. At the same time, social mobility has stalled: stories of rags to riches were common in the 1970s, but are very unusual today. Only the scions of the wealthy families have a chance to occupy prominent positions in business or public service.

There is nothing exceptional in this trajectory. It has been well documented that income inequality is growing almost everywhere in the world (Atkinson 2015; Piketty 2013), and inheritance is again more important than earned income to define the economic status of the vast majority of individuals, even in more mobile and meritocratic societies. We also know that progressive income taxes are an essential tool to prevent ever-greater concentration of income and wealth, and the fact that taxes have become less progressive than they used to be is one of several causes of growing inequality.

Growing inequality is breeding discontent in many countries, and the dilemmas that this poses are a focus of growing political attention. The sustainability of inequality is a question mark for the future of many countries, and of democratic as well as authoritarian regimes. The Gulf oilproducing countries are no different-except that not much attention is paid to the issue.

Yet sustainability and inequality are very closely related. Sustainability requires reduced reliance on expatriate labor, increased national 
employment in the private sector, increased productivity and wages, more value-added creation in market conditions rather than in the government sector; in other words, more independent and economically active citizens. The political system would inevitably be impacted: will the transition be traumatic?

\section{REFERENCES}

Arab News (2018) Saudi Aramco, SABIC sign deal with Britain's 'Wood Group' to develop world's largest crude oil to chemicals project, Riyadh 11/03/2018. Atkinson, Anthony n.d.(2015) Inequality: What Can Be Done, Harvard University Press, Cambridge, MA.

CID (n.d.) (Center for International Development, Harvard University), Atlas, Glossary, available at http://atlas.cid.harvard.edu/learn/glossary, last accessed 2019.06.26.

DOI (2017) 'Strengthening the Department of the Interior's Energy Portfolio', Order No. 3351, US Department of the Interior.

FT (2018a) Wealthy Saudis sit on cash as purge casts shadow over investment $24 / 07 / 2018$.

FT (2018b) Scientists attempt to breathe new life into CCS 20/09/2018.

Gulf News (2016) Carbon capture company Al Reyadah launched in Abu Dhabi $05 / 11 / 2016$.

Hausmann, n.d.Ricardo, César Hidalgo et al. (2014) The Atlas of Economic Complexity: Mapping Paths to Prosperity, MIT.

Hertog, n.d.Steffen (2018) "Challenges to the Saudi Distributional State in the Age of Austerity" in Madawi Al-Rasheed Salman's Legacy: the Dilemmas of a New Era in Saudi Arabia, Oxford University Press Oxford.

IEA (2016) 20 Years of Carbon Capture and Storage: Accelerating Future Deployment, Paris.

IEA (2018a) Outlook for Producer Economies-WEO Special Report, Paris.

IEA (2018b) IEA and UK kick-start a new global era for CCUS press release $28 / 11 / 2018$.

IEA (2018c) World Energy Outlook 2018, Paris.

IEA (2019) The Future of Hydrogen: Seizing today's opportunities, Paris.

IPCC (2018) Global Warming of $1.5^{\circ} \mathrm{C}$ Special Report October 2018, Geneva.

KAPSARC (2018) Decarbonizing Oil: The Role of $\mathrm{CO}_{2}$-Enhanced Oil Recovery $\left(\mathrm{CO}_{2}\right.$-EOR), Riyadh.

Luciani (2005) "From Private Sector to National Bourgeoisie: Saudi Arabian Business" in Paul Aarts and Gerd Nonneman eds. Saudi Arabia in the Balance, NYU Press, New York. 
Masnadi (2018) Mohammad et al. "Global Carbon Intensity of Crude Oil Production" in Science vol. 361 issue 6405.

McGlade, Christopher (2019) Commentary: Can $\mathrm{CO}_{2}$-EOR really provide carbon-negative oil? IEA, Paris.

PDO (2017) Miraah Solar Plant Delivers First Steam Oilfield press release $11 / 2 / 2017$.

Piketty, n.d.Thomas (2013) Le capital au XXI siècle, Seuil, Paris.

Sachs, Jeffrey (2007) "How to Handle the Macroeconomics of Oil Wealth?" in Macartan Humphreys, Jeffrey Sachs and Joseph Stiglitz eds. Escaping the Resource Curse, Columbia University Press, New York.

White House (2019) President Donald J. Trump Is Unleashing American Energy Dominance, fact sheet, May 19, 2019.

Open Access This chapter is licensed under the terms of the Creative Commons Attribution-NonCommercial-NoDerivatives 4.0 International License (http:// creativecommons.org/licenses/by-nc-nd/4.0/), which permits any noncommercial use, sharing, distribution and reproduction in any medium or format, as long as you give appropriate credit to the original author(s) and the source, provide a link to the Creative Commons licence and indicate if you modified the licensed material. You do not have permission under this licence to share adapted material derived from this chapter or parts of it.

The images or other third party material in this chapter are included in the chapter's Creative Commons licence, unless indicated otherwise in a credit line to the material. If material is not included in the chapter's Creative Commons licence and your intended use is not permitted by statutory regulation or exceeds the permitted use, you will need to obtain permission directly from the copyright holder. 